\title{
Economische
}

\section{theorievorming omtrent de onderneming (deel 1)}

Prof. Dr. P. W. Moerland

\section{Inleiding ${ }^{1}$}

In de economische wetenschap zijn interessante ontwikkelingen gaande inzake de theorievorming omtrent de onderneming. De wortels van dit denken voeren in belangrijke mate terug naar de jaren dertig, die op dit punt zeker niet als depressief mogen worden aangemerkt. Toen is een basis gelegd voor het vakgebied van de industriële organisatie, dat nadien is uitgegroeid tot een volwaardige tak van wetenschapsbeoefening. Daarin wordt het functioneren van de onderneming bestudeerd in de context van marktstructuur en concurrentieprocessen. Er zijn evenwel nog andere belangwekkende bijdragen, waar overigens lange tijd betrekkelijk weinig aandacht aan is besteed, maar die thans een ware renaissance doormaken. Gedoeld wordt op de inzichten van Berle en Means (1932) aangaande de scheiding van leiding en eigendom binnen de onderneming, en de briljante gedachtensprong van Coase (1937), dat de onderneming behalve als onderdeel van de markt ook kan worden opgevat als een alternatief voor de markt. De verlate bloei van deze noties krijgt de laatste decennia gestalte in een aanzwellende stroom van publikaties in het kader van de agency-theorie en de transactiekostentheorie. Deze paradigma's zou men beide kunnen beschouwen als loten aan de eveneens tot wasdom komende stam van wat genoemd kan worden een economische organisatietheorie. $^{2}$

Ronald $\mathrm{H}$. Coase toonde in zijn baanbrekende bijdrage 'The nature of the firm' uit 1937 een wezenlijk nieuwe invalshoek op de ontstaansgrond van de onderneming. Met recht kan worden gesteld dat hij als een van de grondleggers van de hedendaagse theorie van de onderneming mag worden beschouwd. De inmiddels 81-jarige Coase, Brit van geboorte en jarenlang als hoogleraar verbonden aan de University of Chicago, ontving op 15 oktober 1991 de (23e) Nobelprijs voor economie. Daarmee is nog eens onderstreept dat het belang van zijn inzichten niet gemakkelijk kan worden overschat. In dit artikel komt bovengenoemde gedachtensprong van Coase nader aan bod.

Het vraagstuk van de onderneming als economisch instituut heeft de laatste jaren hoge actualiteitswaarde door het hele proces van 'reshaping' dat zich voltrekt in de vorm van overnames, verzelfstandigingen en andere herschikkingen. Ook het instituut markt is onderhevig aan een voortdurende dynamiek: concurrentie maakt plaats voor samenwerking, samenwerking voor beheersing, en beheersing weer voor concurrentie, overigens niet noodzakelijk in deze volgorde en ook niet zonder dat er sprake is van allerlei hybride vormen. $^{3}$

Markten en ondernemingen staan in een intrigerende, steeds weer wisselende verhouding tot elkaar. Ondernemingen maken niet alleen deel uit van het marktsysteem, maar vormen ook een alternatief coördinatiemechanisme voor de

Prof. Dr. P. W. Moerland studeerde bedrijfseconomie aan de Erasmus Universiteit Rotterdam en promoveerde in 1978 cum laude op het proefschrift 'Firm behaviour under taxation', eveneens aan de EUR. Van 1980-1988 hoogleraar Bedrijfskunde aan de Rijksuniversiteit Groningen. Sedert 1988 hoogleraar Bedrijfseconomie aan de Katholieke Universiteit Brabant, Tilburg. 


\section{MAB}

markt. Er vindt een voortdurende substitutie plaats tussen beide mechanismen, bijvoorbeeld door het afstoten van activiteiten naar de markt of juist door uitschakeling van de markt zoals bij integratie in de bedrijfskolom. Tenslotte is er de markt waarop ondernemingen als zodanig object van ruil zijn: de overnamemarkt. De begrippen markt en onderneming hangen dus nauw met elkaar samen: we kennen de onderneming als participant in de markt, als alternatief voor de markt, en als ruilobject op de markt. Het is opvallend hoe weinig inzicht er tot nu toe bestaat inzake de onderlinge verhouding van deze beide begrippen. ${ }^{4}$ Zoals gezegd doemt er geleidelijk aan enig perspectief op aan de wetenschappelijke horizon, zij het dat dit zeker nog aan scherpte behoort te winnen. Deze verhandeling is gewijd aan beschouwingen omtrent de theorie van de onderneming. Daarbij zal de relatie met het marktbegrip regelmatig aan de orde komen. Ook zal aandacht worden geschonken aan de rol van het ondernemerschap in het kader van de zich in een markteconomie voltrekkende concurrentieprocessen.

Dit artikel is opgesplitst in twee gedeelten.

Deel I bevat hierna de volgende paragrafen:

Paragraaf 2 Wat is een onderneming?

Paragraaf 3 Waarom bestaan er ondernemingen?

Paragraaf 4 Aantasting van de holistische visie

Paragraaf 5 Informatie-asymmetrie

Deel II zal zijn gewijd aan:

Paragraaf 6 Agency-theorie

Paragraaf 7 Transactiekostentheorie

Paragraaf 8 Wedijver en ondernemerschap

Paragraaf 9 Samenvattend overzicht

\section{Wat is een onderneming?}

Ondernemingen vervullen een wezenlijke rol in het proces van maatschappelijke voortbrenging. Zij dragen bij aan de produktie en distributie van goederen en diensten met het oog op de bevrediging van behoeften.

Waar komen deze ondernemingen vandaan? Waarin vinden zij hun bestaansgrond? Wat moet onder het begrip onderneming worden verstaan? Op deze vragen is geen simpel antwoord moge- lijk. Dit wekt misschien bevreemding, aangezien we ons in de praktijk een tamelijk concreet beeld kunnen vormen van wat een onderneming is, door te denken aan voorbeelden als Unilever of de bakkerij op de hoek. De theoretische beantwoording van bovenstaande vragen is echter minder eenvoudig. Inmiddels is de gedachtenvorming binnen de economische wetenschap over aard en oorsprong van het verschijnsel onderneming reeds ver gevorderd, zij het dat deze nog niet geheel tot een eind is gekomen. In deze bijdrage wordt uitvoerig ingegaan op de 'stepping stones' die leiden tot de thans vigerende opvattingen met betrekking tot de onderneming. Alvorens daartoe over te gaan zal het traditionele, micro-economische concept van de onderneming kort worden gekenschetst en van enkele kritische kanttekeningen worden voorzien.

\section{De traditionele 'theory of the firm'}

De traditionele micro-economische 'theory of the firm' heeft zich, anders dan de naamgeving wellicht doet vermoeden, van oudsher vooral bezig gehouden met de bestudering van naar evenwicht tenderende markten en niet zozeer met de bestudering van het functioneren van ondernemingen als zodanig. Voor zover dat laatste wel het geval is, is de benaderingswijze nogal rudimentair. De onderneming wordt daarbij in feite voorgesteld als een 'black box', zijnde een technische produktiefunctie, ingebed tussen factor- en produktmarkten, en opererend onder één of ander holistisch maximalisatiepostulaat. In deze traditie wordt de onderneming opgevat als een gegeven economische institutie, welke deel uitmaakt van een markteconomie, en waarvan aard noch oorsprong worden verklaard.

Deze traditionele zienswijze wordt door velen als te beperkt ervaren, en wel om uiteenlopende redenen.

1 In de eerste plaats wordt aanvaarding van de onderneming als een gegeven instituut onbevredigend geacht. Met name Coase stelde zich in 1937 de vraag welke de ontstaansgrond is van ondernemingen. Waarom bestaan er eigenlijk ondernemingen? Op deze vraag wordt in paragraaf 3 ingegaan.

2 In de tweede plaats is het holisme, de opvatting 


\section{MAB}

als zou met de onderneming een éénduidige doelstelling worden nagestreefd, aan kritiek onderhevig. Met name Berle en Means hebben er reeds in 1932 op gewezen dat zich bij veel ondernemingen in feite een scheiding aan het voltrekken was tussen de managementfunctie en de financieringsfunctie. De belangen van het management aan de ene kant en die van de aandeelhouders aan de andere kant kunnen onderling divergeren, hetgeen de veronderstelling van één ondubbelzinnige centrale ondernemingsdoelstelling tot een discutabele maakt. Ook dit vraagstuk wordt hierna verder uitgewerkt (in paragraaf 4).

3 In de derde plaats is door diverse auteurs, destijds met name verbonden aan het Carnegie Mellon-instituut, zoals March en Simon (1958), Cyert en March (1963), bezwaar aangetekend tegen het maximalisatiepostulaat. In hun zogenaamde 'behavioral theory of the firm' wordt het functioneren binnen ondernemingen eerder gekenmerkt door het streven naar een bevredigend resultaat ('satisficing behavior') dan naar een zo hoog mogelijk resultaat. Een karakteristiek element van deze gedragswetenschappelijke theorie is de veronderstelde begrensdheid van de menselijke rationaliteit, 'bounded rationality', vanwege zijn tekortschietende capaciteit om alle relevante informatie te vergaren en te verwerken. Dit rationaliteitsbegrip speelt tevens een belangrijke rol in de transactiekostentheorie van Williamson, die in paragraaf 7 aan bod komt.

4 In de vierde plaats wordt de traditionele 'theory of the firm' veelal geplaatst in de context van een statisch concurrentiebegrip dat is gebaseerd op het (comparatief statische) evenwichtsdenken. Auteurs als Schumpeter (1939), Hayek (1949), Kirzner (1973), en De Jong (1989) benadrukken evenwel de betekenis van de ondernemersfunctie tegen de achtergrond van dynamische marktprocessen. Aan deze benaderingswijze wordt aandacht besteed in paragraaf 8 .

\section{Waarom bestaan er ondernemingen?}

De micro-economische theorie houdt zich voor- namelijk bezig met de bestudering van markten. Daarbij speelt de werking van het prijsmechanisme een essentiële rol. Produktie en distributie worden gestuurd door relatieve prijzen, welke een coördinatie bewerkstelligen tussen economische subjecten, die optreden als aanbieders van produktiefactoren en vragers van produkten. Ondernemingen maken deel uit van deze markteconomie als vragers van produktiefactoren en aanbieders van produkten. Maar waar komen deze ondernemingen vandaan? Wat is hun raison d'être?

Coase toonde in zijn baanbrekende bijdrage 'The nature of the firm' uit 1937 een wezenlijk nieuwe invalshoek op de ontstaansgrond van de onderneming. Hij schetst de onderneming als zijnde een substituut, als een alternatief coördinatiemechanisme voor de markt. 'Outside the firm, price movements direct production, which is co-ordinated through a series of exchange transactions on the market. Within a firm, these market transactions are eliminated and in place of the complicated market structure with exchange transactions is substituted the entrepreneur-co-ordinator, who directs production. It is clear that these are alternative methods of co-ordinating production' (p. 388). De keuze voor het ene dan wel het andere mechanisme wordt afhankelijk gesteld van de kosten verbonden aan de werking ervan. Als het moeilijk of kostbaar is om de prijs van een produkt of prestatie te 'ontdekken', kan het dienstig zijn om het marktmechanisme te vervangen door een andere wijze van communiceren en coördineren, via het stichten van een onderneming (of meer algemeen: een organisatie). Coase stelt ( $p$. 390): 'The main reason why it is profitable to establish a firm would seem to be that there is a cost of using the price mechanism. The most obvious cost of 'organising' production through the price mechanism is that of discovering what the relevant prices are'. Doorslaggevend voor de keuze tussen de markt en de onderneming als alternatieve coördinatiemechanismen is hun beider relatieve efficiency in termen van informatieverzameling en informatieverwerking. Door het internaliseren van de afstemming omtrent ruilhandelingen binnen de onderneming kan er onder bepaalde omstandigheden worden bespaard op 


\section{MAB}

transactiekosten, zijnde de 'cost of using the price mechanism'.

De besparingen kunnen worden gevonden in een vermindering van het aantal benodigde transacties dan wel in een wijziging van de aard van de transacties. Voor wat dit laatste betreft kan men denken aan het afsluiten van een 'relationeel contract' in plaats van een serie (eenmalige) 'discrete contracten' voor de verwerving van een bepaalde produktiefactor. ${ }^{5}$ Vergelijk het arbeidscontract voor onbepaalde duur, waarbij een werknemer de beschikkingsmacht over zijn arbeidskracht vrijwillig overdraagt aan een ondernemer-coördinator. Dan behoeven de afzonderlijke activiteiten niet voortdurend via een prijssignaal op de arbeidsmarkt te worden gereguleerd, maar kan worden volstaan met een flexibele raamovereenkomst, waarbinnen de ondernemer is geautoriseerd om rechtstreekse aanwijzingen te geven aangaande de te verrichten werkzaamheden. Aldus kan worden afgezien van een gedetailleerde vastlegging vooraf van specifieke instructies ten behoeve van allerlei denkbare, zich mogelijk voordoende omstandigheden ('contingencies'). Het onderhandelen over, schrijven en doen naleven van dergelijke gespecificeerde contracten is of wel ondoenlijk of wel zeer kostbaar. Bovendien zijn de interne mogelijkheden tot communiceren, prikkelen en beoordelen veelal meer verfijnd en omvattend dan de externe signalen via de markt.

Het belang van de inzichten die door Coase zijn ontwikkeld, kan niet gemakkelijk worden overschat. De visie op de onderneming als een alternatief voor de markt ligt in feite ten grondslag aan de later door Williamson uitgewerkte transactiekostentheorie (zie paragraaf 7 ).

Het onderkennen van een verder strekkende ruilbetrekking tussen aanbieders van produktiefactoren en een ondernemer-coördinator kan worden beschouwd als een wezenlijke toevoeging aan de tot dan toe geldende economische theorie van de onderneming. Anders dan een gegeven 'black box' voor het tot stand brengen van slechts op prijssignalen berustende ruiltransacties (de 'invisible hand' van het marktmechanisme), ziet
Coase de onderneming als een bewust gekozen economische organisatievorm, waarbinnen ruimte is voor autoriteit, instructie en beoordeling (de 'visible hand' van de ondernemer). De interne ondernemingsstructuur en de vormgeving van de contractuele relaties met de daarin participerende economische subjecten komen naar voren. Hiermee wordt in feite een eerste aanzet gegeven voor de later tot verdere ontwikkeling komende agency-theorie (zie paragraaf 6).

Tenslotte schenkt Coase expliciet aandacht aan het vraagstuk van de informatieverwerving en de daarmee verbonden kosten. Ook dit houdt een breuk in met de traditionele economische theorie, waarin veelal werd uitgegaan van het bestaan van volkomen informatie dan wel de mogelijkheid tot kosteloze verkrijging daarvan. De moderne economische theorie is doortrokken van het informatieprobleem, waarop Coase in feite reeds heeft gepreludeerd (zie paragraag 5). Met recht kan dan ook worden gesteld dat Coase als een van de grondleggers van de hedendaagse theorie van de onderneming mag worden beschouwd.

\section{Aantasting van de holistische visie}

De opvatting als zou met behulp van de onderneming een éénduidige doelstelling worden nagestreefd domineert in feite het denken binnen de neo-klassieke economische theorie. Het gaat dan om maximalisatie van de winst, of zoals in de financierings- en beleggingstheorie wordt verondersteld, om het maximaliseren van de waarde van het vermogen voor de eigenaren. Dit holistische uitgangspunt wordt op de proef gesteld zodra verschillende categorieën van betrokkenen in de onderneming met uiteenlopende belangen in beschouwing worden genomen.

In hun invloedrijke boek 'The modern corporation and private property' uit 1932, wezen Berle en Means evenwel reeds op het fenomeen dat zich bij grote corporatieve ondernemingen een ontkoppelingsproces aan het voltrekken was tussen de managementfunctie en de financieringsfunctie ('separation of ownership and control'). De opkomst van de vennootschappelijke rechtsvorm 


\section{MAB}

maakte deze scheiding van de ondernemersfunctie in besturen en financieren mogelijk. Berle en Means zagen dat er bij veel corporatieve ondernemingen vanaf de eeuwwisseling in feite sprake was van een wijde verspreiding van het aandelenbezit over een groot aantal vermogensverschaffers, die elk slechts over een zeer gering belang in de vennootschap beschikten. Deze ontwikkeling bracht in de visie van Berle en Means met zich mee dat de wettelijke eigenaren van het ondernemingsvermogen niet meer bij machte waren om dergelijke grote corporaties te leiden en de bestuurlijke macht over het bedrijfsgebeuren uit handen gaven aan professionele managers. Aldus ontstond de 'management controlled firm' waarin de managers het voor het zeggen hebben, hun eigen belangen kunnen nastreven ten koste van de aandeelhouders, en zich daarmee begeven in 'corporate plundering'.

Berle en Means zagen hierin een bedreigende ontwikkeling in de richting van een oprukkend 'managerial capitalism', waarbij het management de feitelijke bestuurlijke macht over de onderneming verkrijgt en die voor een deel te eigen nutte zal aanwenden, zonder dat daarbij sprake kan zijn van een effectieve controle door de aandeelhouders. Critici ${ }^{6}$ hebben er later op gewezen, dat deze hypothese nimmer empirisch is bevestigd. Zij stellen dat de corporatieve ondernemingsvorm juist bijzonder geschikt is om bedrijfsuitoefening op grote schaal te kunnen realiseren, omdat twee positieve elementen daarin worden samengebracht: enerzijds de aanwezigheid van vele externe aandeelhouders (met beperkte aansprakelijkheid), die het risico over hun beleggingen kunnen spreiden door diversificatie en anderzijds de mogelijkheid om de meest gekwalificeerde bestuurskracht te selecteren, los van een eventuele vermogensinbreng.

Niettemin vormt het vraagstuk van de mogelijkerwijs uiteenlopende belangen van managers en financiers nog steeds een bron van wetenschappelijke belangstelling. Het was Williamson (1964), die als een van de eersten een poging tot consistente theorievorming inzake de motivatie van het management heeft verricht. Hij gaat ervan uit, dat managers tot op zekere hoogte hun eigen wensen voorop stellen, die niet in overeenstemming behoeven te zijn met de belangen van de vermogensverschaffers, hetgeen blijkt uit 'overbestaving' en andere vormen van (schadende) overdaad, zoals al te luxueuze huisvesting, inrichting en uitstapjes. De manager zou handelen alsof hij een nutsfunctie maximaliseert onder omstandigheden waarin discretionaire ruimte ligt besloten voor de bevrediging van eigen behoeften en wel onder de restrictie (p. 37) 'that reported profits be greater than or equal to the minimum acceptable level of profit demanded'.

Marris (1963) gaat ervan uit dat managers zich vooral laten leiden door een groeidoelstelling ten aanzien van de ondernemingsomvang. Ook Baumol (1962) zocht het in deze richting (maximalisatie van de verkoopopbrengsten). Al deze auteurs hebben gepoogd om een formeel theoretisch kader te creëren, waarbinnen het gedrag van de 'managerial firm' kan worden verklaard. Daarbij substitueert men het neo-klassieke uitgangspunt van winst- of waardemaximalisatie voor een andere doelstellingsvariabele die onder randvoorwaarden wordt gemaximaliseerd. De doelstelling sluit veelal aan bij diverse ingrediënten uit de individuele nutsfunctie van de manager, zoals macht, prestige, status, inkomen, luxe, en dergelijke.

Van grote betekenis voor de bestudering van divergerende belangen is de in paragraaf 6 te bespreken agency-theorie.

\section{Informatie-asymmetrie}

In de traditionele micro-economische theorie wordt veelal uitgegaan van een situatie van volkomen informatie ('perfect foresight'), of kosteloze verkrijging daarvan, met betrekking tot produkten en prestaties. In de economische werkelijkheid is echter bij veel ruilbetrekkingen sprake van een gebrek aan volkomen informatie. Bovendien zal de wel beschikbare of verkrijgbare informatie veelal niet gelijkelijk zijn verdeeld over de betrokken economische subjecten. Zo zal de verkoper van een produkt in het algemeen een informatievoorsprong hebben op de aspirant-koper, en dat geldt niet alleen in het roemruchte geval van 


\section{MAB}

tweedehands auto's. Maar ook het omgekeerde kan voorkomen, zoals bijvoorbeeld bij de verkoop van levensverzekeringen, in welk geval de koper mogelijk beter op de hoogte is van specifieke risico's dan de verkoper. Dit schept een ex ante informatieprobleem, waarbij sprake is van informatie-asymmetrie tussen aspirant-ruilpartners, hetwelk kan leiden tot 'adverse selection'.

Het was Akerlof (1970), die dit vraagstuk naar voren bracht onder verwijzing naar de werking van de markt voor tweedehands auto's. Deze gingen (toentertijd) naar zijn waarneming tegen onbegrijpelijk lage verkoopprijzen van de hand. De oorzaak hiervan is volgens Akerlof gelegen in de omstandigheid dat de kwaliteit van een tweedehands auto niet bekend is aan de aspirantkoper ('is het misschien een latent wrak, een 'lemon'?). Deze laatste vormt zich een idee van de waarschijnlijkheidsverdeling betreffende het kwaliteitsniveau van de verzameling auto's en zal hooguit bereid zijn een prijs te bieden welke overeenstemt met een gemiddeld te verwachten kwaliteitsniveau. Dit zal er echter toe leiden dat alleen auto's met een lager dan gemiddeld kwaliteitsniveau worden aangeboden, aangezien een handelaar die een betere dan een gemiddelde kwaliteit in huis heeft niet bereid zal zijn te verkopen tegen die in zijn perceptie te lage biedprijs. Rationele aspirant-kopers zullen deze constellatie op hun beurt voorzien en gaan ertoe over om hun waarschijnlijkheidsverdeling neerwaarts bij te stellen. Voorgaande argumentatie herhaalt zich, waardoor de markt als uitsluitend op prijssignalen gebaseerd coördinatiemechanisme uiteindelijk dreigt te falen. De aanbieder van auto's met een meer dan gemiddeld kwaliteitsniveau heeft behoefte aan en belang bij het afgeven van andere dan prijssignalen aan de markt, welke zijn distinctieve hoedanigheid tot uitdrukking brengen. Zo zou hij een bepaalde kwaliteitswaarborg kunnen verlenen die hem doet onderscheiden van andere aanbieders. Voorwaarde is wel dat een dergelijk signaal niet door de anderen dient te kunnen worden geïmiteerd, dan wel, indien zulks wel mogelijk is, uitsluitend tegen hogere kosten. Aan deze laatste eis zal in het onderhavige voorbeeld van de markt voor tweedehands auto's allicht zijn voldaan, aangezien het leveren van een relatief mindere kwaliteit naar verwachting gepaard zal gaan met een hoger beroep op de afgegeven garantie.

Het vraagstuk van informatie-asymmetrie beperkt zich overigens niet tot tweedehands markten. Ook in markten voor nieuwe produkten worden pogingen ondernomen om informatieverschillen omtrent het gebodene te reduceren, en wel door beide partijen. Zo kan de verkoper zijn produkten voorzien van een keurmerk om aldus een kwaliteitssignaal uit te zenden naar de koper, of hij kan proberen een reputatie te vestigen door de ontwikkeling van herkenbare merken of formules. Denk ook aan de mogelijkheid om garantie te verlenen op onderdelen bij duurzame gebruiksartikelen. Een koper kan op zijn beurt de kwaliteit van het gebodene (doen) inspecteren, zoals bijvoorbeeld op een fruitveiling gebeurt door steekproefsgewijs te controleren of de appels onder in de kist werkelijk even mooi zijn als de bovenste laag.

De door Akerlof geïnitieerde signaaltheorie heeft inmiddels zijn intrede gedaan bij het bestuderen van andere belangrijke markten die veelvuldig gekenmerkt worden door het bestaan van ex ante informatie-asymmetrie, zoals de arbeidsmarkt (Spence, 1973) en de vermogensmarkt (Ross, 1977, Leland en Pyle, 1977). Managers, die van mening zijn dat de onderneming die zij besturen door de vermogensmarkt wordt ondergewaardeerd, hebben er belang bij om signalen uit te zenden omtrent de in hun visie hogere echte waarde. Zij kunnen dit bijvoorbeeld doen door de financiële leverage op te voeren ten teken dat zijzelf de financiële kracht van de onderneming hoog aanslaan (Myers en Majluf 1984). De aankondiging van een dergelijke maatregel leidt veelal tot een stijging van de beurskoers ('goed nieuws'), terwijl een verkleining van de leverage ratio een daling van de beurskoers ('slecht nieuws') tot gevolg blijkt te hebben.

Behalve ex ante informatie-asymmetrie bestaat er ook ex post informatie-asymmetrie, dat wil zeggen een verschil in informatie tussen econo- 


\section{MAB}

mische subjecten nadat zij een ruilbetrekking met elkaar zijn aangegaan. Dit type informatieprobleem houdt het risico in van 'moral hazard', waarbij de beter geïnformeerde partij zijn voorsprong kan exploiteren ten nadele van de andere partij. Zo is denkbaar dat een manager zich minder goed inspant dan optimaal zou zijn voor de externe aandeelhouders, zonder dat zulks voor hen is waar te nemen. De manager zal geneigd zijn om gunstige resultaten in verband te brengen met door hemzelf beheersbare factoren (zoals het ontwikkelen van een goede strategische visie) en, omgekeerd, ongunstige resultaten met voor hem niet beheersbare factoren (zoals het optreden van 'valutaire tegenwind'). lets dergelijks kan gelden voor een employee in relatie tot zijn chef. De employee zal geneigd zijn om een hoge produktiviteit toe te schrijven aan zijn eigen inzet, maar een lage produktiviteit aan verouderde machines of inferieure grondstoffen.

Het verschijnsel van 'moral hazard' wordt veelal in verband gebracht met verborgen actie ('hidden action'), en het verschijnsel van 'adverse selection' met verborgen informatie ('hidden information').

Beide vormen van asymmetrische informatie, vóór en na het aangaan van een ruilbetrekking, impliceren een economisch probleem inzake de inrichting van ruilbetrekkingen en de allocatieve werking van transacties, dat met name vanaf de jaren zeventig sterk in de wetenschappelijke belangstelling staat. Behalve de hiervoor genoemde signaaltheorie heeft de agency-theorie in zeer belangrijke mate bijgedragen tot vergroting van het inzicht in deze problematiek.

\section{Literatuur}

Akerlof, G. A., 1970, The market for 'lemons'; quality and the market mechanism. Quarterly Journal of Economics, vol. 84, pp. 488-500.

Alchian, A. A. en H. Demsetz, 1972, Production, information costs, and economic organization, American Economic Review, vol. 62, pp. 777-795.

Barkema, H. G., 1988, Variations in ownership structure, managerial pay packages and managerial effort across firms and industries, an agency-theoretic perspective, Academisch proefschrift, Groningen.

Barnea, A., R. A. Haugen en L. W. Senbet, 1985, Agency problems and financial contracting, Prentice Hall, Englewood Cliffs, N.J.

Baumol, W. J., 1962, On the theory of expansion of the firm, American Economic Review, vol. 52, pp. 1078-1087.

Berle, A. A. en G. C. Means, 1932, The modern corporation and private property, Macmillan, New York.

Bouma, J. L., 1966, Ondernemingsdoel en winst: een confrontatie van enkele theorieën van het ondernemingsgedrag, Stenfert Kroese, Leiden.

Brown, W.B., 1984, Firm-like behavior in markets; the administered channel, International Journal of Industrial Organization, vol. 2, pp. 263-276.

Coase, R. H., 1937, The nature of the firm, Economica, vol. 4, pp. 386-405

Cyert, R. M. en J. G. March, 1963, A behavioral theory of the firm, Prentice Hall, Englewood Cliffs, N.J.

Cheung, S. N. S., 1983, The contractual nature of the firm, Journal of Law and Economics, vol. 26, pp. 1-21.

Cooper, R. en T. W. Ross, 1985, Product warranties and double moral hazard, Rand Journal of Economics, vol. 16, pp. 103113

De Alessi, L., 1983, Property rights, transaction costs, and Xefficiency: an essay in economic theory, American Economic Review, vol. 73, pp. 64-81.

Douma, S. W., 1987, Op weg naar een economische organisatietheorie: agency theorie, Maandblad voor Accountancy en Bedrijfshuishoudkunde, vol. 61, pp. 420-432.

Douma, S. W., 1988, Op weg naar een economische organisatietheorie: de transactiekosten benadering, Maandblad voor Accountancy en Bedrijfshuishoudkunde, vol. 62 , pp. 2-11.

Fama, E. F., 1980, Agency problems and the theory of the firm, Journal of Political Economy, vol. 88, pp. 288-307.

Fama, E. F. en M. C. Jensen, 1983a, Separation of ownership and control, Journal of Law and Economics, vol. 26, pp. 301326.

Fama, E. F. en M. C. Jensen, 1983b, Agency problems and residual claims, Journal of Law and Economics, vol. 26, pp. 326-351.

Furubotn, E. G. en S. Pejovich, 1972, Property rights and economic theory: a survey of recent literature, Journal of Economic Literature, vol. 10, pp. 1137-1162.

Harris, M. en A. Raviv, 1979, Optimal incentive contracts with imperfect information, Journal of Economic Theory, vol. 20 pp. 231-259.

Hayek, F. A. 1949, Individualism and economic order, London.

Hendrikse, G. W. J., en H. Schreuder, 1987, Economische organisatietheorie, Economisch Statistische Berichten, vol. 72, pp. 810-815.

Hendrikse, G. W. J. en H. Schreuder, 1989, Economische theorie van de interne organisatie, Maandblad voor Accountancy en Bedrijfseconomie, vol. 63, pp. 417-423.

Hessen, R., 1983, The modern corporation and private property: a reappraisal, Journal of Law and Economics, vol. 26, pp. 273-289.

Holmström, B., 1979, Moral hazard and observability, Bell Journal of Economics, vol. 10, pp. 74-91. 


\section{MAB}

Imai, K. en H. Itami, 1984, Interpenetration of organization and market, Japan's firm and market in comparison with the US, International Journal of Industrial Organization, vol. 2, pp. 285-310.

Jensen, M. C. en W. H. Meckling, 1976, Theory of the firm: managerial behavior, agency costs and ownership structure, Journal of Financial Economics, vol. 3, pp. 305-360.

Jensen, M. C. en R. S. Ruback, 1983, The market for corporate control: the scientific evidence, Journal of Financial Economics, vol. 11, pp. 5-50.

Jong, H.W. de, 1981, Marktorganisatie, mededinging en prijsvorming, Economisch Statistische Berichten, vol. 66, pp. 1268-1280.

Jong, H.W. de, 1989, Dynamische markttheorie, 4e herziene druk, Stenfert Kroese, Leiden.

Kirzner, 1. M., 1973, Competition and entrepreneurship, The University of Chicago Press, Chicago.

Kneppers-Heynert, E. M., 1988, Een economische en juridische analyse van franchising tegen de achtergrond van een property rights- en transactiekostenbenadering, Academisch proefschrift, Groningen.

Knight, F., 1921, Risk, uncertainty, and profit, The University of Chicago Press, Chicago.

Lambers, H. W., 1959, De industriële ondernemer in een bewegende economische orde, Ondernemend Nederland, Leiden.

Leland, H. E. en D. H. Pyle, 1977, Informational asymmetries, financial structure, and financial intermediation, Journal of Finance, vol. 32, pp. 371-387.

Macneil, I. R., 1978, Contracts: adjustment of long-term economic relations under classical, neoclassical, and relational contract law, Northwestern University Law Review, vol. 72, pp. 854-906.

Manne, H., 1965, Mergers and the market for corporate control, Journal of Political Economy, vol. 73, pp. 110-120.

March, J. G. en H. A. Simon, 1958, Organizations, New York.

Marris, R., 1963, A model of the 'managerial' enterprise, Quarterly Journal of Economics, vol. 77, pp. 185-209.

Marris, R. en D. C. Mueller, 1980, The corporation, competition and the invisible hand, Journal of Economic Literature, vol. 18 , pp. 32-63.

Moerland, P. W., 1982, Zeggenschap, risico en de verdeling der toegevoegde waarde, oratie Rijksuniversiteit Groningen, Stenfert Kroese, Leiden.

Moerland, P. W., 1984, Enkele beschouwingen over de vorming en ontvlechting van concerns, in: Financiering en belegging: stand van zaken anno 1984 (red. W. M. van den Bergh, e.a.), Erasmus Universiteit Rotterdam, pp. 245-255.

Moerland, P. W., 1989a, Het ontstaan van een economische organisatietheorie, in: Bedrijfsunde op weg naar 1990 , trends en ontwikkelingen (red. C. van Dam), Kluwer, Deventer.

Moerland, P. W., 1989b, De overnemingsmarkt: theorie, empirie en regelgeving, oratie Katholieke Universiteit Brabant, Vuga Uitgeverij B.V., 's-Gravenhage; tevens verschenen in: Maandblad voor Accountancy en Bedrijfseconomie, vol. 63, pp. 143-161.
Morck, R., Shleifer, A. en R. W. Vishny, 1989, Alternative mechanisms for corporate control, American Economic Review, vol. 79, pp. 842-852.

Myers, S. C . en N. S. Majluf, 1984, Corporate financing and investment decisions when firms have information that investors do not have, Journal of Financial Economics, vol. 13, pp. 187-221.

Noorderhaven, N. G., 1990, Private competence and public responsibility; anatomy of a government-firm relationship. Academisch proefschrift, Groningen.

Rosenberg, N., 1983, Comments on Robert Hessen, 'The modern corporation and private property: a reappraisal', Journal of Law and Economics, vol. 26, pp. 291-296.

Ross, S. A., 1973, The economic theory of agency: the principal's problem, American Economic Review, vol. 63, pp. 134-139.

Ross, S. A., 1977, The determination of financial structure: the incentive-signaling approach, Bell Journal of Economics, vol. 8, pp. 23-40.

Schreuder, H., 1983, Economic theories of organization: an overview and assessment of some recent developments, research memorandum 1983-11, Economic and Socist Institute of the Free University, Amsterdam.

Schreuder, H., Economie (en) bedrijven, 1985, oratie Rijksuniversiteit Limburg, Van Gorcum, Assen/Maastricht.

Schumpeter, J. A., 1939, Business cycles (two volumes), New York/London.

Simon, H. A., 1957, Models of man, Wiley, New York.

Spence, M., 1973, Job market signaling, Quarterly Journal of Economics, vol. 87, pp. 355-374.

Stigler, G. J. en C. Friedland, 1983, The literature of economics: the case of Berle and Means, Journal of Law and Economics, vol. 26, pp. 237-268.

Stiglitz, J. E., 1974, Incentives and risk sharing in sharecropping Review of Economic Studies, vol. 41, pp. 219-255.

Williamson, O. E., 1964, The economics of discretionary behavior: managerial objectives in a theory of the firm, Prentice Hall, Englewood Cliffs, New York.

Williamson, O. E., 1975, Markets and hierarchies: analysis and antitrust implications: a study in the economics of internal organization. Free Press, New York.

Williamson, O. E., 1981, The modern corporation: origins, evolution, attributes, Journal of Economic Literature, vol. 19 , pp. 1537-1568.

Williamson, O. E., 1985, The economic institutions of capitalism: firms, markets, relational contracting, Free Press/Collier MacMillan, New York/London.

\section{Noten}

1 De auteur is Prof. Dr. H. G. Barkema, Prof. Dr. S. W. Douma, Drs. H. Oosterhout, Dr. G. W. J. Hendrikse en Prof. Dr. F. M. Tempelaar erkentelijk voor hun commentaar bij een eerdere versie van dit artikel.

2 Vergelijk eerdere Nederlandse bijdragen op dit punt van onder anderen Moerland $(1982,1984,1989 a)$, Schreuder $(1983,1985)$, Douma (1987, 1988), Hendrikse en Schreuder (1987, 1989). 


\section{MAB}

3 Voor een belangwekkende beschrijving van deze verschijnselen zij verwezen naar De Jong (1989).

4 Zie bijvoorbeeld Cheung (1983), Imai en Itami (1984).

5 Het begrip 'relationeel contract' wordt door Macneil (1978) gesteld tegenover 'discreet contract'. Bij dit laatste type contract is sprake van een eenmalige ruilhandeling tussen voor elkaar onbekende partijen. Van een relationeel contract is sprake indien tussen de ruilpartners een verder strekkende relatie tot stand komt voor langere duur ten behoeve van een reeks van ruilhandelingen. Het hier gemaakte onderscheid wordt ook gemaakt door Kneppers-Heynert (1988) met betrekking tot 'franchising' en door Noorderhaven (1990) met betrekking tot de verhouding tussen onderneming en overheid.

6 Vergelijk het speciale nummer van de Journal of Law and Economics, dat in 1983 is uitgebracht ter gelegenheid van het feit dat toen inmiddels een halve eeuw was verstreken sinds de publikatie van Berle en Means. Het bevat bijdragen van onder anderen Hessen, Rosenberg, Stigler en Friedland. 